\title{
Kinetic fractionation and extreme mineral-scale heterogeneity in the Earth's mantle
}

\author{
ROMAIN TILHAC ${ }^{1,2}$, CARLOS J. GARRIDO $^{1}$, KÁROLY \\ HIDAS $^{3}$ AND BEÑAT OLIVEIRA ${ }^{2}$ \\ ${ }^{1}$ Instituto Andaluz de Ciencias de la Tierra (IACT/CSIC) \\ ${ }^{2}$ Macquarie University \\ ${ }^{3}$ Instituto Geológico y Minero de España (IGME) \\ Presenting Author: romain.tilhac@csic.es
}

Variations in clinopyroxene REE concentrations in mantle xenoliths and abyssal peridotites provide unique insights into the magmatic processes at play in the subcontinental and suboceanic mantle. These variations are usually interpreted in terms of igneous processes occurring in melt-solid equilibrium, with important conclusions on the melting and melt transport mechanisms. Yet, the extent to which magmatic processes occur in disequilibrium remains a fundamental question in the Earth's mantle. We here report extreme mineral-scale heterogeneity of REE concentrations spanning nearly three orders of magnitude within single $<1-\mathrm{mm}$ clinopyroxene crystals from a spinel lherzolite xenolith hosted in continental alkali basalts. The clinopyroxenes show strong LREE-to-MREE fractionation and marked core-to-rim differentiation with increasing $(\mathrm{La} / \mathrm{Sm})_{\mathrm{N}}=$ $0.3-11.0$ and positive $\mathrm{Eu}$ anomalies $\left[\left(\mathrm{Eu} / \mathrm{Eu}^{*}\right)_{\mathrm{N}}=1.0-1.8\right]$. This extreme heterogeneity covers most of the range observed in entire suites of subcontinental and suboceanic samples, commonly accounted for by variable degrees of melting and melt-interaction processes requiring pressure and temperature gradients and/or spatial variations incompatible with the fractionation observed here at the mm-scale.

Our diffusion and percolation-diffusion models rather suggest that such fractionation reflects the existence strong chemical gradients and highlight the role of kinetic fractionation, with important geochemical implications. This observation indeed shows that extreme mantle heterogeneities not only result from long-term recycling of differentiated material but may also be produced by internal magmatic processes. We envisage that their development could notably be promoted during deep volatileinduced incipient melting beneath mid-ocean ridges and show that they are probably sustainable over relatively long periods of time. As such, mineral-scale heterogeneities could be the rule rather than the exception in the mantle, likely to be underestimated by on-axis lavas whose compositional variability is limited by shallow mixing processes. Lastly, we emphasize that kinetic fractionation associated with diffusion may induce strong Eu anomalies which would explain the ghost plagioclase signature observed in some basalts and melt inclusions. Similar conclusions can be drawn for other geochemical proxies, such as the MREE-to-HREE fractionation ascribed to the presence of garnet, as recently suggested by our disequilibrium reactive transport models ([1]).

[1] Oliveira, Afonso \& Tilhac (2020), Journal of Petrology 61- 